\section{Cat on a hot tin roof...}

She looked at me and said "I am very scared...please do something. Can't you operate on me to remove the tumor? My tummy is bloated, I can't sleep at night". Eyes averted, I replied that we will do everything we can and that things will work out. We are planning to start a new targeted agent that has shown considerable promise. It will take a few weeks for the drug to kick in and then she will start feeling better.

I knew that things will not work out. She was dying. Dying of an advanced intrabdominal sarcoma that had been resistant to everything that we had thrown at it, including a briefly successful surgical resection.

I asked her to wait outside the office while I further discussed the treatment with her mother. Her twenty one years old daughter, about to graduate as an engineer, desperately wants to live, she said. There must be some new medications to 'dissolve' the mass. I tried to explain, this time looking in the mother's eyes, that this is a resistant cancer in the best of situations. Now, with failure of multiple lines of chemotherapy the predicament was dire. Tears well up..."How do I face her when she pleads for life?" I ask about her siblings - she has a young brother who dotes on her.

I start becoming very uncomfortable - I fix an appointment with the psychiatrist and clinical psychologist for a counselling session. I specifically request them to do something for the severe anxiety that this girl is experiencing.

Years of practice in a vocation where I have to often treat people with only a few weeks or months to live have benumbed my senses. Every now and then, however, there is a chink in the armour. The encounter with this family refuses to leave me. What made me so uncomfortable and distressed? Perhaps, this time, a young girl eager to live got through to me! Not a case of advanced drug resistant sarcoma! A mother's unimaginable distress at seeing her daughter waste to death also perhaps got through to me!

\begin{tabular}{|l|l|}
\hline \multicolumn{3}{|c|}{ Access this article online } \\
\hline Quick Response Code: & Website: \\
\hline & \\
\hline
\end{tabular}

There has been, and rightly so, great recent emphasis on pain and symptom control in terminally ill cancer patients. But what does one do to help a patient cope with the fear of impending death? That this girl was very scared of dying affected me more than anything else. Despite the oft romanticised accounts of heroic battles with terminal disease, the truth is that most humans are unable to face their mortality with composure and equanimity - especially the young ones. Medical oncologists, by the nature of their calling, encounter these feelings very often. And yet they are utterly ill equipped to deal with the ramifications. The stark reality of human finiteness, including their own, is brought home again and again. And not suddenly, as would perhaps happen in an emergency room or an acute care unit. A long term bond with another human being snaps in slow motion... over and over. The call to the psychologist was perhaps as much for myself as it was for the girl and her family.

Do we get compassion fatigued? Studies suggest that we do. ${ }^{[1]}$ Is fatigue the only way to insulate ourselves from the exacting demands of our profession? Does fatigue compartmentalise itself to our professional lives? Do we also get compassion fatigued in our interpersonal relationships? That there are hardly any answers to these questions suggests that we participate in a 'conspiracy of silence'.

There is an unforgettable sequence in 'Cat on a Hot Tin Roof' in which the 'Big Daddy' character with terminal cancer refuses to accept morphine from his son - "You get the pain and you know you're alive...". The quest to live is the most potent emotion in humans...and is sometimes difficult to endure when projected on to oneself from another.

So...speaking to myself...does the cat jump off the hot tin roof...

Sudeep Gupta

Editor-in-Chief,

Professor of Medical Oncology, Breast Cancer Working Group, Tata Memorial Hospital, Mumbai, Maharashtra, India. E-mail: editor@ijmpo.org

\section{REFERENCE}

1. Fetter KL. We grieve too: One inpatient oncology unit's interventions for recognizing and combating compassion fatigue. Clin J Oncol Nurs 2012;16:559-61.

How to cite this article: Gupta S. Cat on a hot tin roof.... Indian J Med Paediatr Oncol 2013;34:65. 